Journal of Education and Educational Development

8(1), 194-217, 2021

DOI: http://dx.doi.org/10.22555/joeed.v8i1.518

\title{
Impact of Accreditation on Improvement of the Teacher Education Programs/Institutions in Pakistan
}

\author{
Uzma Perveen \\ Abdul Wali Khan University Mardan, Pakistan \\ Muhammad Idris \\ Abdul Wali Khan University Mardan, Pakistan \\ Amir Zaman \\ Abdul Wali Khan University Mardan, Pakistan
}

\begin{abstract}
In Pakistan, an accreditation system has been introduced to accredit teacher education programs and initiatives are being taken to begin the registration, licensing, and certification process of teachers. The Higher Education Commission (HEC) Pakistan has declared the accreditation of teacher education programs mandatory. All the institutions offering any graduate-level teacher education programs are required to get the accreditation of their programs. The National Accreditation Council for Teacher Education (NACTE) has accredited around 450 programs of more than 180 public and private sector teacher education institutions, which include colleges and universities, offering teacher education all over Pakistan. The current research is descriptive, which focused on providing an accurate description of the impact of teacher education programs, and the institutions equipped with the facility. This method was preferred as the study primarily sought to describe and understand the stakeholders' response to the impact of accreditation on the institution and program improvement, rather than ascertaining any cause-and-effect relationship. The criterion for sample selection was based on the participation of the faculty concerned, the head of department (HOD), and the external evaluators in the accreditation process of the programs, offered by the institutions. A five-point Likert scale was developed to collect data from the stakeholders (HOD, teacher educators, and external evaluators). The use
\end{abstract}


of mean, $S D$, provided the basis for calculation, application, and interpretation of t-test and ANOVA. The results show that majority of participants were of the view that the accreditation process has a high impact on the improvement of teacher education programs.

Keywords: accreditation, higher education commission, impact, programs, quality assurance, teacher education

\section{Introduction}

Renowned researchers and educationists acknowledge that teachers are doing a great service to society by supporting the main stakeholders, the students, through educational ventures. Teaching is a function, which is aimed at achieving the set goals and guiding the predetermined growth in their students, irrespective of their age. Teachers create and develop a strong bond with their students through interaction, and by supporting them for better outcomes. With the catchphrase, "a born teacher", we have made the problem too easy. The assumption that it is not possible to become a teacher through learning, and that the skills are innate, has resulted in a series of disadvantages about the actual role that they play to nurture and mold the students to become future leaders. This has led to neglecting the professional development of teachers. They mostly continue using the lecture method, which is outdated and has been discarded in the developed countries. The viewpoint that 'the teacher is born, not made', held by various people, certainly is a contributing factor to the scanty regard, paid to the opportunities for initial and in-service training.

In Pakistan, reforms were required in all areas of teacher education that include: pre-service education, training, standardization of qualifications, continuous professional development; teacher remuneration, career progression, status, governance, and management of the teaching workforce. The growth of the private sector added new complexities to the teaching profession, which are needed to be addressed by reforming the system. A significant implication of these policy reforms would be that teacher education would become a responsibility of the providers of higher education and other services at the post-secondary education level. The reforms in teacher education had to be carried out in tandem with the development of quality in education in general, and in higher education in particular. Therefore, Pakistan has chosen a broad strategy to address the issue of teacher effectiveness 
by introducing key reforms for the teacher education programs and institutions. The underlying assumption is that reforms in teacher education programs will create a cadre of better-prepared and more motivated teachers, who will shoulder an education system that will gradually improve its performance (Government of Pakistan, Ministry of Education 2004).

The accreditation of teacher education programs has been declared mandatory by the HEC. All institutions, offering the graduate-level teacher education program, are required to get the accreditation of their programs. Complete accreditation process comprises of two stages: initially, a zero accreditation for one year is awarded to a program, keeping in view the adequacy and quality of its resources (human, financial, and learning), infrastructure, vision, mission, and legal mandate of the institution. It is ensured that the programs and all their stakeholders are in a safe and conducive environment. It is a probationary type of year/period and the successful completion leads to the second standard of accreditation. At the second stage, formal accreditation is awarded for three years.

The purpose of initiating the accreditation process for teacher education was to ensure and improve the quality of teacher education programs and institutions. Formal accreditation is being conducted since 2010-2011. Almost 10 years have passed when the process of accreditation was launched, which is continuing to carry its objectives. However, no third-party evaluation has been carried out by the government, and no study has been conducted to evaluate the role, impact, and effectiveness of the accreditation of teacher education, to gauge how far the accreditation has developed to improve the quality of teacher education in the country. It has, therefore, become imperative to conduct a study to investigate The Impact of the Accreditation on Teacher Education Program/ Institutions in the Country. This research study will try to answer the following research questions:

1. What is the impact of accreditation on the improvement of teacher education programs and institutions?

2. What is the nature and magnitude of accreditation impact on the private and public sector teacher education institutions?

3. How accreditation process of teacher education can further be improved? 


\section{Literature Review}

There is growing evidence that the quality of teachers is the most important educational resource in our schools. Therefore, greater attention must be paid to the factors that shape the quality of teachers. Teachers have engaged themselves in a major role than ever in our technologically advanced and skill-based economy, wherein the academic underperformers are perceived to be left behind (Swelled, 2014). The teacher quality translates directly into students' learning. A properlyprepared teacher impacts student assessment more than the big apple, and other background aspects of the pupil, like minority status, language, and poverty. (Darling-Hammond, 2006). Teacher education providers should have the capacity and ability to first attract college students with high academic potential and then work with them properly to meet the ever-evolving demands of learning and teaching in the twenty-first century. Achieving such capacity in the providers is a collective responsibility of the nation, university, and the profession.

\section{The Global Trends Towards Quality Assurance}

Quality has become a central concept in many discussions in education in many countries since the early 1980s. This led to the rapid increase in quality assurance mechanisms, driven by three trends: globalization, internationalization, and accountability, which successively have shaped quality assurance mechanisms.

\section{The Role of Quality Assurance Agencies}

Quality assurance agencies are designed to stop unwanted consequences, like political interference occurring from the standard assessment process. As Nerve and Vought's (1991) study shows, the governments reduce direct controls over education to support the trend towards deregulation of central control of institutions. Subsequently, national quality assurance agencies have come to exchange governments' direct control over the higher education institutions (HEIs). Most national quality assurance agencies have the facility which Finch (1997) calls 'legitimate authority to practice state power and pursue their aims through legislation and funding. Harvey and William (2010) argue that quality assurance agencies have led to a mushrooming of qualification frameworks and a bent to accredit everything. Although these are unintended consequences of QA systems, both Stensaker (2002) and Newton (2002) contend out that the foremost positive aspect of the QA system is that increased institutional transparency. Consistent 
with Newton (2002), the evaluations have made the 'black box of higher education more open and quantifiable, bringing it close to student needs. The main issue with quality assurance agencies is what degree of independence they ought to have and whether such independence will cause greater trust or more government control of higher education.

The quality assurance agencies have additionally been established at regional and international levels like the Council for Pedagogy Certification (CHEA) that could be a personal, noncommercial, national organization that coordinates certification activity within the US. CHEA represents quite 3,000 faculties and universities and sixty national, regional and specialized accreditors.

Asia Pacific Quality Network (APQN) is a corporation operating to boost the standard of higher education in Asia and also the Pacific region through strengthening the work of quality assurance agencies and increasing cooperation between them. The International Network for Quality Assurance Agencies in Pedagogy (INQAAHE) could be a worldwide association of over two hundred organizations, active within the theory and observance of quality assurance in pedagogy. A great majority of its members are unit quality assurance agencies that operate in various ways, though the Network also welcomes alternative organizations as the associate members.

\section{Purpose of Certification}

Accreditation serves four main purposes in both higher education or TE contexts (Banji, 2010; CEDEFOP, 2011a; IIEP, 2010a; Kis, 2005; Martin \& Sanyal, 2006).

- Quality control

- Accountability

- Quality improvement

- Facilitation of student mobility

\section{Impact of Accreditation}

1. Assures the general public that institutions have met rigorous standards.

2. Establishes common professional standards for the preparation of teachers 
and other school personnel.

3. Encourages excellence in curriculum, student performances, faculty, and resources in college and university faculties of education.

4. Links national standards for teacher preparations with national standards for student learning.

5. Helps to mobilize adequate resources to organize quality personnel to enhance student learning.

6. Brings previously unaccredited institutions into the profession's emerging quality-assurance system.

\section{Teacher Education in Pakistan: The Opportunities and Challenges}

A comparative overview of the literature on teacher education in Pakistan and the international context recognizes some critical gaps within the understanding and practices of teacher education in the country. In Pakistan, in recognition of teachers' essential role within the reforms, which have consistently been recognized throughout consecutive national education policies, teacher education has been considered a key area of the reforms (Ahmed, 2012). Moreover, teacher education tends to worry about the technical aspect of teaching, which involves subject knowledge and a hard and fast set of skills, required to transfer that knowledge to student-teachers (Ali, 2008; Ahmed, 2012; Memon, 2010; Sarwar, 2006; Saeed, 2010). Literature has emphasized that other critical dimensions of teacher education including personal, social, and moral, are believed to possess received little or no attention (Mohammed, 2006). Also, the literature on teacher education in Pakistan emphasized the normal transmission paradigm of teacher education, aiming at the transmission of data (Cole \& Knowles, 2000). It is often noted from these paradigms that teaching may be a technical activity and, therefore, the role of an educator as a technician is to equip himself/herself with the required knowledge and skills, required by the teaching task (Cocheran-Smith \& Fires, 2001).

The international context indicates that many countries have initiated specific measures to improve the quality of teacher education, like program accreditation, licensing, and certification. Pakistan has also initiated certain specific actions and mechanisms to ensure the quality of teacher education. To control the quality of education particularly, professional education, the concept of accreditation 
emerged in 1900. To ensure the quality of professional education in different areas, accreditation councils have been working in almost all developed and developing countries for different professions, to accredit the professional institutions and programs. Pakistan is no exception; it has accreditation councils like Pakistan Engineering Council, Pakistan Medical and Dental Council, Pakistan Nursing Council, Pakistan Bar Council, and many others for their related professions.

The Higher Education Commission (HEC), a federal body responsible for quality assurance of higher education, established National Accreditation Council for Teacher Education (NACTE) in December 2006. NACTE is authorized to assess and evaluate the quality of teacher education programs, conducted by the public and private sector colleges and universities. While the HEC accredits all higher education institutions in Pakistan, NACTE's responsibility is to accredit the teacher education programs only (NACTE, 2009a).

\section{Methodology}

\section{Research Design}

This study was designed to evaluate the impact of accreditation on the improvement of the teacher education programs/institutions in Pakistan. It was descriptive, which focused on providing an accurate description of the impact of teacher education programs and institutions. This method was preferred as the study primarily sought to describe and understand the stakeholders' response to the impact of accreditation on the institution and program improvement, rather than determining any cause-and-effect relationship. Additionally, in the absence of any empirical evidence or research in the subject area, a descriptive research design was the most appropriate approach to gather accurate information about the phenomenon. A quantitative research design, therefore, was employed for the present study to meet the objectives and answer the research questions.

\section{Sample}

The population of the study comprised all teachers of 184 public and private sector accredited teacher education institutions of all four provinces of Pakistan including Federal, Gilgit-Baltistan, and AJK areas. All the external evaluators of NACTE and HODs of accredited teacher education programs/ institutions were also part of the population. 


\section{Table 1}

Province-wise Details of the Accredited Teacher Education Institutions

\begin{tabular}{ccccc}
\hline Sr.\# & Province & Universities & Colleges & Total \\
\hline 1 & Punjab & 23 & 11 & 34 \\
2 & Sindh & 25 & 41 & 66 \\
3 & KPK & 15 & 6 & 21 \\
4 & Baluchistan & 8 & 20 & 28 \\
5 & Federal & 4 & 0 & 4 \\
6 & GB & 1 & 4 & 5 \\
7 & AJK & 7 & 19 & 26 \\
8 & Total & 83 & 101 & 184 \\
\hline
\end{tabular}

The multistage sampling technique was used for the selection of samples. At the first stage, approximately $20 \%$ of accredited institutions were selected through convenient sampling. In the second stage, three teacher educators and the HODs from each institution were selected. The selection of the external evaluators was made province/area wise through the purposive sampling technique as it involves a selection criterion to ensure that the participants provide the requisite information needed for the research study. The criteria for sample selection were based on the participation of the faculty concerned, the HOD, and external evaluators in the accreditation process of the programs, offered by the institutions.

The following table describes the details of the sample:

\section{Table 2}

Province-wise Distribution of the Sample

\begin{tabular}{|c|c|c|c|c|c|}
\hline Sr.\# & Provinces & Accredited Institutions Universities \& Colleges & HOD & $\begin{array}{l}\text { Teacher } \\
\text { Educator }\end{array}$ & Evaluator \\
\hline \multirow[t]{9}{*}{1} & Punjab & BZU, Multan & 1 & 3 & 10 \\
\hline & & LCWU, Lahore & 1 & 3 & \\
\hline & & Fatima Jinnah Women University, Rawalpindi. & 1 & 3 & \\
\hline & & FC University, Lahore & 1 & 3 & \\
\hline & & Ali Institute of Education, Lahore & 1 & 3 & \\
\hline & & The University of Wah Cantt. & 1 & 3 & \\
\hline & & Collage of teacher education Bisali & 1 & 3 & \\
\hline & & Fazaia College of Education for Women, Lahore & 1 & 3 & \\
\hline & & Total & 8 & 24 & 10 \\
\hline
\end{tabular}




\begin{tabular}{|c|c|c|c|c|c|}
\hline \multirow[t]{9}{*}{2} & \multirow[t]{9}{*}{ Sindh } & University of Karachi & 1 & 3 & \multirow[t]{8}{*}{10} \\
\hline & & University of Sindh & 1 & 3 & \\
\hline & & SBBU, Nawabshah & 1 & 3 & \\
\hline & & I.B.A., Sukkur & 1 & 3 & \\
\hline & & SZABIST Karachi & 1 & 3 & \\
\hline & & IOBM Karachi & 1 & 3 & \\
\hline & & GECE (M), Larkana & 1 & 3 & \\
\hline & & GECE (M), Hyderabad & 1 & 3 & \\
\hline & & Total & 8 & 24 & 10 \\
\hline \multirow[t]{7}{*}{3} & \multirow[t]{7}{*}{ KPK } & University of Hazara & 1 & 3 & \multirow[t]{6}{*}{8} \\
\hline & & University of Haripur & 1 & 3 & \\
\hline & & SBBU, Peshawar & 1 & 3 & \\
\hline & & Sarhad University, Peshawar & 1 & 3 & \\
\hline & & Meezan College of Education, Swabi & 1 & 3 & \\
\hline & & College of Education, PAF Peshawar & 1 & 3 & \\
\hline & & Total & 6 & 18 & 8 \\
\hline \multirow[t]{5}{*}{4} & \multirow[t]{5}{*}{ Baluchistan } & University of Baluchistan, Quetta & 1 & 3 & \multirow[t]{4}{*}{5} \\
\hline & & SBK University, Quetta & 1 & 3 & \\
\hline & & GCET, Quetta & 1 & 3 & \\
\hline & & GCE, Quetta & 1 & 3 & \\
\hline & & Total & 4 & 12 & 5 \\
\hline \multirow[t]{4}{*}{5} & \multirow[t]{4}{*}{ Federal } & International Islamic University, Islamabad & 1 & 3 & \multirow[t]{3}{*}{10} \\
\hline & & NUML, Islamabad & 1 & 3 & \\
\hline & & Preston University Islamabad Campus, Islamabad & 1 & 3 & \\
\hline & & Total & 3 & 9 & 10 \\
\hline \multirow[t]{4}{*}{6} & \multirow[t]{4}{*}{ GB } & Karakoram International University, Gilgit & 1 & 3 & \multirow[t]{3}{*}{3} \\
\hline & & $\begin{array}{l}\text { Government College of Education (Women), Gilgit } \\
\text { Baltistan }\end{array}$ & 1 & 3 & \\
\hline & & FG Elementary College, Skardu & 1 & 3 & \\
\hline & & Total & 3 & 9 & 3 \\
\hline \multirow[t]{5}{*}{7} & \multirow[t]{5}{*}{ AJK } & University of Azad Jammu\& Kashmir, Muzaffarabad & 1 & 3 & \multirow[t]{4}{*}{4} \\
\hline & & $\begin{array}{l}\text { Mirpur University of Science \&Technology (MUST), } \\
\text { Mirpur, AJK }\end{array}$ & 1 & 3 & \\
\hline & & GCET (F) Muzaffarabad & 1 & 3 & \\
\hline & & GCET (F) Rawalakot & 1 & 3 & \\
\hline & & Total & 4 & 12 & 4 \\
\hline \multirow[t]{2}{*}{ Total } & Pakistan & Grand Total & 36 & 108 & 50 \\
\hline & & & \multicolumn{3}{|c|}{194} \\
\hline
\end{tabular}




\section{Instrument}

A five-point Likert scale was developed to collect data from the stakeholders (HOD, teacher educators, and external evaluators). The questionnaire for the study was designed, keeping in view the objectives, research questions, and characteristics of the sample. It comprised and covered all six dimensions of the research questions, related to the impact of accreditation on teacher education programs and institutions in Pakistan. The questionnaire consisted of 44 statements and included six to seven questions on each aspect for the independent opinions of the respondents.

Reliability and validity are the two concepts associated with the trustworthiness of qualitative research. Reliability refers to the consistency, suitability, or repeatability of the research instrument (Johnson \& Christensen, 2008), while validity refers to "the correctness or truth of a reference" (Johnson \& Christensen, 2008, p. 253). The reliability of the instruments was checked by using the test, retest method. The content and face validity of both tools were determined with the expert opinion of senior teachers/educators and researchers in the context of accreditation.

An analysis was conducted and reliability coefficient alpha was computed on a statistical package for the social sciences (SPSS). Pilot test data revealed the reliability coefficient of the hundred items test to be 0.74 . It was considered acceptable according to the rule of thumb, suggested by Fraenkel and Wallon (1993). The reliability of a test for research purposes should be at least 0.70 or preferably higher.

\section{Data Collection}

The data was gathered through the following modes:

The researcher approached the HOD/ chairpersons of the departments concerned of the teacher education universities with a request to administer the tools to the sample. Necessary guidelines were also provided on the tools to facilitate the respondents.

In this mode, the researcher contacted and communicated with the head of the departments concerned under the guidance of the supervisor to seek their 
cooperation in the data collection process, particularly in the universities of other provinces.

Permission was taken from the authorities concerned, heads, teacher educators, and external evaluators. Tools were administered to 36 HODs, 108 teacher educators, and 50 external evaluators from each province. The return rate was $85 \%$ as the researcher herself approached the sample during the COVID-19 pandemic. In each institute, the tool was distributed, guidelines were given to fill in the questionnaire, and background information was also provided. Several questionnaires were sent to the HODs, teacher educators, and external evaluators, who filled in those and mailed them to the researcher. The presence of the researcher was helpful for the removal of any ambiguity in any item and avoidance of the missing information. It was made sure that all tools had been filled with full understanding, completed, and collected back.

\section{Data Analysis}

The main purpose of the study was to assess the impact of accreditation on the teacher education institutions in Pakistan. Further, it was aimed at ascertaining the nature and significance of the impact of accreditation on the institutions. There was also the need to compare the magnitude of the impact of accreditation on public and private sector institutions. The population of the study comprised all teachers of 184 public and private sector accredited teacher education institutions of all four provinces of Pakistan including Federal, Gilgit-Baltistan, and AJK areas. All the external evaluators of NACTE and HODs of accredited teacher education programs/ institutions were also part of the population. The selection of the external evaluators was made province/area-wise through the purposive sampling technique, as it involves a selection criterion to ensure that the participants provide the requisite information needed for the research study. The criteria for sample selection were based on the participation of the faculty concerned, HODs, and external evaluators in the accreditation process of the programs, offered by the institutions. Data were organized and analyzed separately. The results were presented in tabular form and final discussions were held to draw findings and conclusions concerning the research questions. The use of Statistical Package for Social Science (SPSS) for mean, SD, t-test, and ANOVA was used for data analysis. The use of mean, SD provided the basis for calculation, application, and interpretation of t-test and ANOVA. Therefore t-test was considered most appropriate to see the significant 
difference between college and university means. ANOVA helped to compare the significant difference in provinces.

\section{Table 3}

Demographic Information of Participants

\begin{tabular}{|c|c|c|}
\hline Variables & Frequency & Percentage \\
\hline \multicolumn{3}{|l|}{ Province } \\
\hline Punjab & 43 & 22.1 \\
\hline Sindh & 50 & 25.6 \\
\hline KPK & 40 & 20.5 \\
\hline Baluchistan & 25 & 12.8 \\
\hline Federal & 16 & 8.2 \\
\hline GB & 13 & 6.7 \\
\hline AJK & 8 & 4.1 \\
\hline \multicolumn{3}{|l|}{ Type of institution } \\
\hline College & 49 & 25.1 \\
\hline University & 146 & 74.9 \\
\hline \multicolumn{3}{|l|}{ Gender } \\
\hline Male & 114 & 58.5 \\
\hline Female & 81 & 41.5 \\
\hline \multicolumn{3}{|l|}{ Experience Type } \\
\hline Evaluator & 50 & 25.6 \\
\hline Teacher Educator & 108 & 55.4 \\
\hline Dean/Director/HOD & 37 & 19.0 \\
\hline \multicolumn{3}{|l|}{ Designation } \\
\hline Lecturer & 57 & 29.2 \\
\hline Assistant Prof. & 84 & 43.1 \\
\hline Associate Prof. & 33 & 16.9 \\
\hline Professor & 21 & 10.8 \\
\hline \multicolumn{3}{|l|}{ Accreditation Experience } \\
\hline Evaluator & 24 & 12.3 \\
\hline Member of Institutional & 39 & 20.0 \\
\hline Accreditation Committee & & \\
\hline Dean/Director/HOD & 15 & 7.7 \\
\hline Both $1 \& 2$ & 69 & 35.4 \\
\hline $1,2 \& 3$ & 48 & 24.6 \\
\hline \multicolumn{3}{|l|}{ Type of Institution } \\
\hline Public & 90 & 46.2 \\
\hline Private & 105 & 53.8 \\
\hline \multicolumn{3}{|l|}{ Accreditation Process } \\
\hline High Impact & 27 & 13.8 \\
\hline Moderate Impact & 159 & 81.5 \\
\hline No Impact & 09 & 4.6 \\
\hline \multicolumn{3}{|l|}{ Program Accreditation } \\
\hline Improvement & 126 & 65.1 \\
\hline Accountability & 60 & 30.8 \\
\hline Formality & 3 & 1.5 \\
\hline Don't have an Idea & 6 & 3.1 \\
\hline
\end{tabular}


Table 3 indicates the percentage of the participants selected from all provinces of Pakistan with the highest percentage from Sindh $(25.6 \%)$ and least from AJK (4.1\%) where most participants were male (58.5\%) and a high percentage of participants belonged to universities. Moreover, most participants (55.4\%) had experience as a teacher educator and most of the participants (43.1\%) were assistant professors in their respective institutions. In addition to this, the participants having experience as both evaluator and member of the accreditation committee have the relative majority of $35.4 \%$. Participants' belonged to both the private and public sectors in an almost equal ratio of $53.8 \%$ and $46.2 \%$.

\section{Table 4}

Views of Participants about Accreditation Process and Program Accreditation

\begin{tabular}{lcc}
\hline Variables & Frequency & Percentage \\
\hline Accreditation Process & 27 & 13.8 \\
High Impact & 159 & 81.5 \\
Moderate Impact & 09 & 4.6 \\
No Impact & & \\
Program Accreditation & 126 & 65.1 \\
Improvement & 60 & 30.8 \\
Accountability & 3 & 1.5 \\
Formality & 6 & 3.1 \\
Don't have an Idea & & \\
\hline
\end{tabular}

Table 4 shows the majority of participants $(81.5 \%)$ said that the accreditation process has a moderate impact on the improvement of teacher education programs while 27 (13.8\%) participants supported the statement of High Impact improvement of teacher education programs. It was an important question to participants about Program Accreditation whether it helped or not to improve teacher education program. One hundred twenty-six (65.1\%) participants said that program accreditation improved teacher education programs while $60(30.8 \%)$ participants said that program accreditation sensitized the accountability of staff, administration, and students. 


\section{Figure 1}

Views of Participant (\%) about Accreditation Process

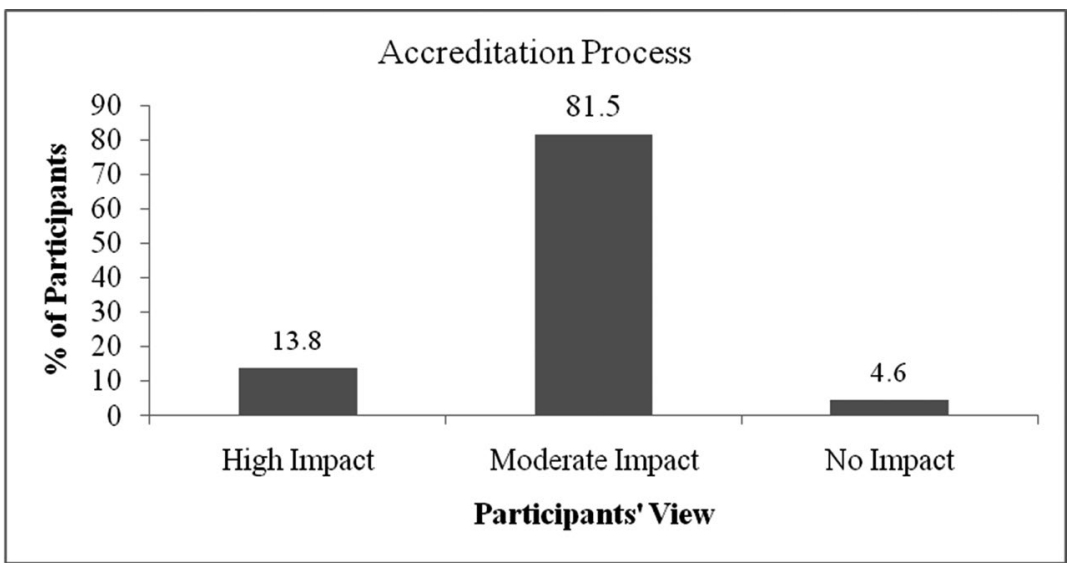

Figure 2

Views of Participants about Program Accreditation

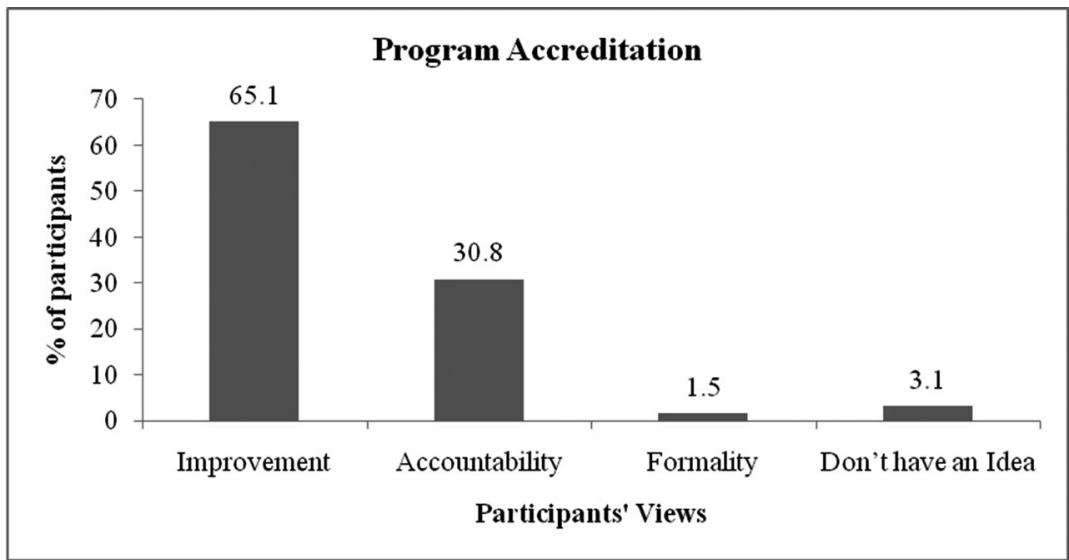

\section{Table 5}

Comparison of Participants Belonging Different Provinces on Standards

\begin{tabular}{|c|c|c|c|c|c|c|c|c|c|c|c|c|c|c|c|c|}
\hline \multirow[b]{2}{*}{ Standards } & \multicolumn{2}{|c|}{ Punjab } & \multicolumn{2}{|c|}{ Sindh } & \multicolumn{2}{|c|}{ KPK } & \multicolumn{2}{|c|}{ Baluchistan } & \multicolumn{2}{|c|}{ Federal } & \multicolumn{2}{|c|}{ GB } & \multicolumn{2}{|c|}{ AJK } & \multicolumn{2}{|c|}{$\begin{array}{c}\text { One-way } \\
\text { ANOVA }\end{array}$} \\
\hline & M & SD & M & SD & M & SD & M & SD & M & SD & M & SD & M & SD & $\mathbf{F}$ & $\mathbf{p}$ \\
\hline $\mathrm{CF}$ & 4.37 & 0.66 & 4.50 & 0.58 & 4.34 & 0.60 & 4.52 & 0.59 & 4.47 & 0.43 & 4.42 & 0.53 & 4.25 & 0.71 & .57 & .755 \\
\hline S1 & 4.37 & 0.56 & 4.52 & 0.45 & 4.42 & 0.45 & 4.41 & 0.54 & 4.60 & 0.31 & 4.31 & 0.51 & 4.31 & 0.55 & .92 & .480 \\
\hline S2 & 4.39 & 0.51 & 4.51 & 0.47 & 4.47 & 0.38 & 4.47 & 0.55 & 4.53 & 0.31 & 4.49 & 0.42 & 4.40 & 0.49 & .35 & .912 \\
\hline S3 & $4.09 *$ & 0.68 & $4.48 *$ & 0.40 & 4.15 & 0.67 & 4.43 & 0.42 & 4.57 & 0.28 & 4.00 & 0.81 & 3.80 & 0.73 & 4.58 & $<.001$ \\
\hline S4 & 4.22 & 0.62 & 4.47 & 0.47 & 4.36 & 0.60 & 4.37 & 0.56 & 4.64 & 0.33 & 4.34 & 0.63 & 3.98 & 0.68 & 2.05 & .062 \\
\hline S5 & 4.22 & 0.56 & 4.51 & 0.49 & 4.37 & 0.54 & 4.44 & 0.52 & 4.62 & 0.30 & 4.36 & 0.65 & 4.34 & 0.54 & 1.82 & .097 \\
\hline S6 & $3.84 *$ & 0.98 & $4.41 *$ & 0.60 & 4.02 & 0.99 & 4.32 & 0.63 & 4.58 & 0.41 & 3.87 & 1.27 & 3.75 & 1.05 & 3.24 & $.005^{* *}$ \\
\hline S7 & 4.14 & 0.59 & 4.44 & 0.51 & 4.32 & 0.60 & 4.25 & 0.53 & $4.75^{*}$ & 0.31 & 4.31 & 0.64 & $4.00 *$ & 0.78 & 3.21 & $.005^{* *}$ \\
\hline
\end{tabular}




\section{Figure 3}

Comparison of mean scores of Responses of participates belong different provinces on standards of Accreditation

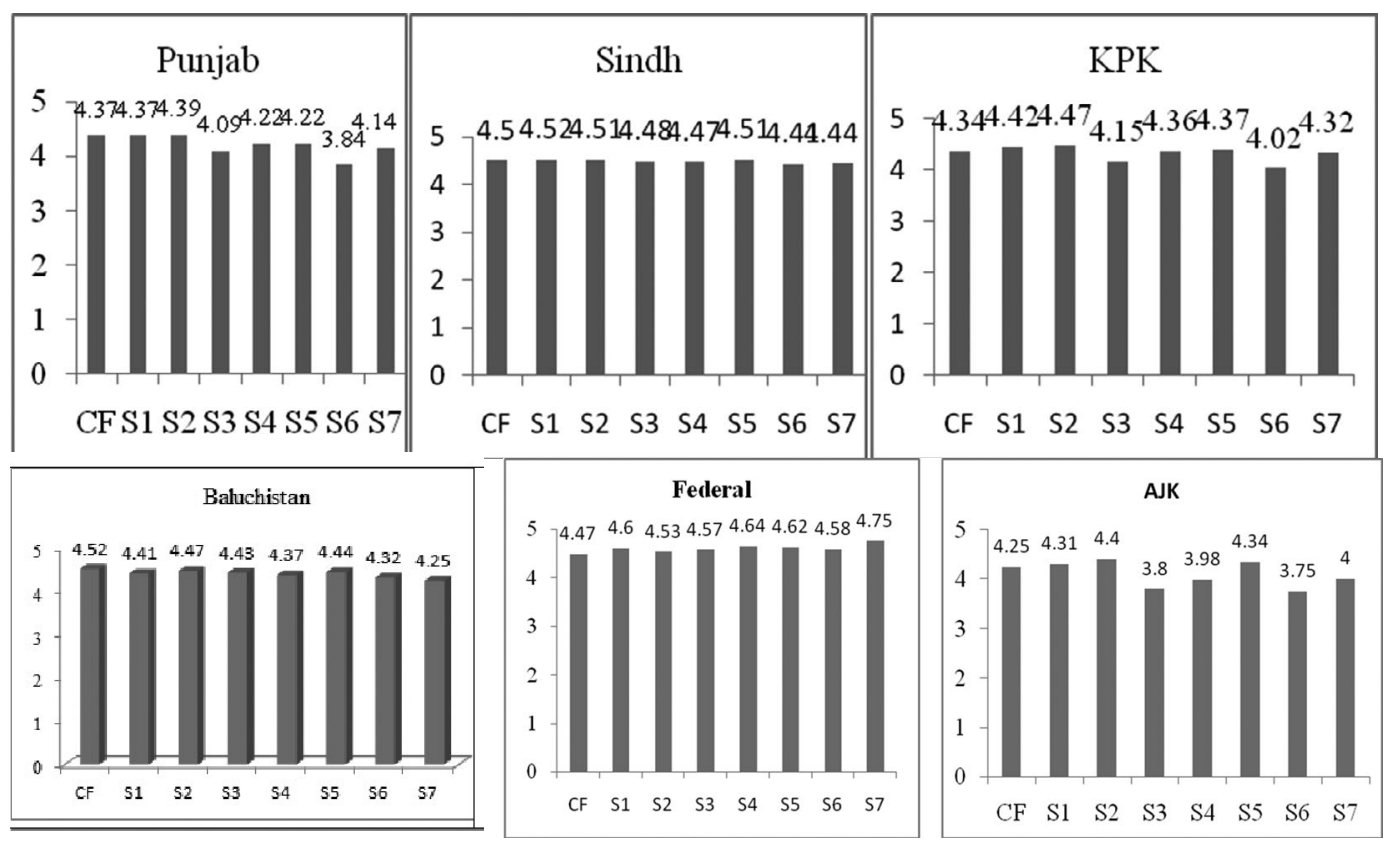

One-way ANOVA was conducted to compare differences in standards of participants belonging to different provinces. The results of One-way ANOVA indicated that there was no significant difference on the statistically significant difference on Conceptual framework Standard-1, Standard-2. Standard-4, Standard-5, Standard-7 regarding participants belong to different provinces of Pakistan. There was a significant difference between Standard-6 and Standard-7. 


\section{Table 6}

Comparison of Participants Belonging to Different Institutions on Standards

\begin{tabular}{|c|c|c|c|c|c|c|}
\hline \multirow[b]{2}{*}{ Standards } & \multicolumn{2}{|c|}{ College } & \multicolumn{2}{|c|}{ University } & \multicolumn{2}{|c|}{$\begin{array}{c}\text { Independent samples } \\
\text { t-test }\end{array}$} \\
\hline & $\mathbf{M}$ & SD & M & SD & $t$ & $\mathbf{p}$ \\
\hline $\mathrm{CF}$ & 4.35 & 0.62 & 4.45 & 0.58 & -1.042 & .299 \\
\hline $\mathrm{S} 1$ & 4.41 & 0.51 & 4.44 & 0.48 & -.383 & .702 \\
\hline S2 & 4.48 & 0.43 & 4.46 & 0.46 & .245 & .807 \\
\hline S3 & 4.07 & 0.74 & 4.34 & 0.54 & -2.737 & $.007 * *$ \\
\hline S4 & 4.32 & 0.62 & 4.38 & 0.55 & -.576 & .565 \\
\hline S5 & 4.37 & 0.60 & 4.41 & 0.50 & -.499 & .618 \\
\hline S6 & 3.93 & 1.08 & 4.22 & 0.79 & -2.030 & $.044^{*}$ \\
\hline S7 & 4.29 & 0.64 & 4.33 & 0.56 & -.427 & .670 \\
\hline
\end{tabular}

The table shows the comparison of participants belonging to different Institutions on standards. Independent samples, t-test was conducted to compare participants belonging to different Institutions on standards. There was no statistically significant difference in Conceptual framework Standard-1, Standard-2. Standard-4, Standard-5, Standard-7 regarding college and university participants. There was a statistically significant difference on Standard-3 and Standard-6. University participants were confident to express their views about the impact of Standard-3 and Standard-6 on quality education as compares to college participants.

\section{Figure 4}

Comparison of college and university participants belonging to different provinces on standards

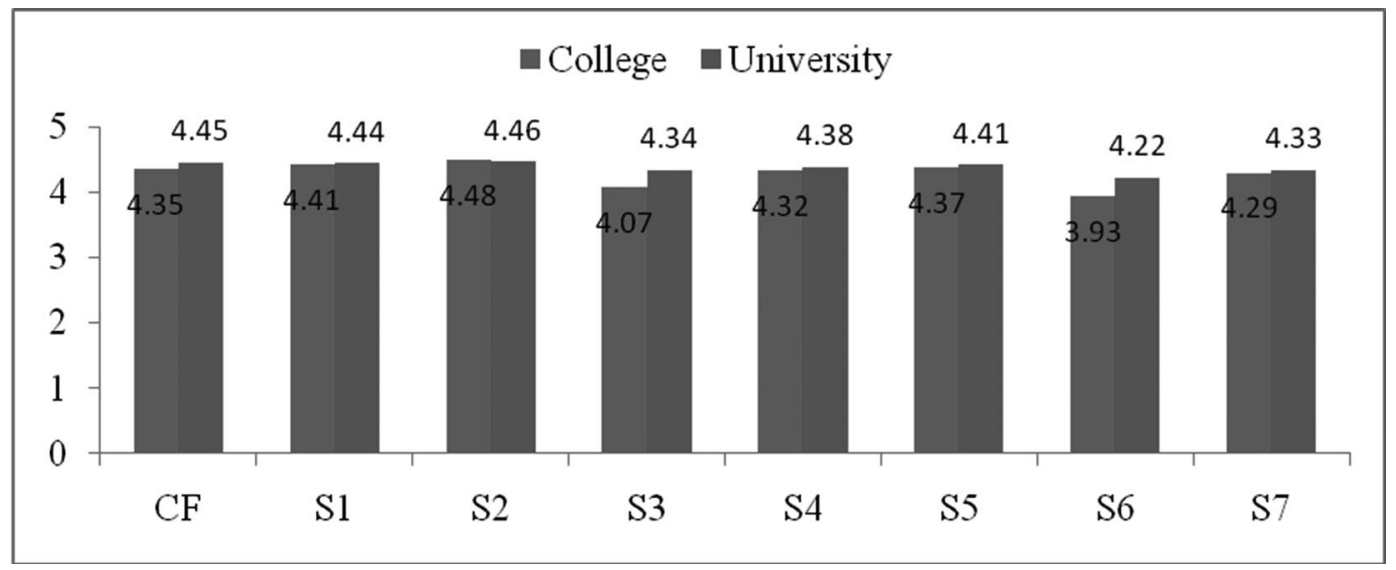




\section{Table 7}

Comparison of Participants Belonging to Public and Private Sector on Standards

\begin{tabular}{|c|c|c|c|c|c|c|}
\hline \multirow[b]{2}{*}{ Standards } & \multicolumn{2}{|c|}{ Public } & \multicolumn{2}{|c|}{ Private } & \multicolumn{2}{|c|}{$\begin{array}{c}\text { Independent samples } \\
\text { t-test }\end{array}$} \\
\hline & $\mathbf{M}$ & SD & M & SD & $\mathbf{t}$ & p \\
\hline $\mathrm{CF}$ & 4.48 & 0.63 & 4.37 & 0.55 & 1.32 & 0.19 \\
\hline S1 & 4.46 & 0.58 & 4.41 & 0.39 & 0.68 & 0.50 \\
\hline S2 & 4.50 & 0.50 & 4.44 & 0.41 & 0.97 & 0.33 \\
\hline S3 & 4.27 & 0.61 & 4.27 & 0.60 & 0.05 & 0.96 \\
\hline S4 & 4.35 & 0.63 & 4.38 & 0.51 & -0.39 & 0.70 \\
\hline S5 & 4.41 & 0.53 & 4.39 & 0.54 & 0.22 & 0.83 \\
\hline S6 & 4.26 & 0.86 & 4.05 & 0.89 & 1.66 & 0.10 \\
\hline S7 & 4.34 & 0.64 & 4.30 & 0.51 & 0.48 & 0.63 \\
\hline
\end{tabular}

Table 7 shows the comparison of participants belonging to the public and private sector on standards. Independent samples t-test was conducted to compare participants belonging to the public and private sector on standards. There was no statistically significant difference on Conceptual framework Standard-1, Standard-2, Standard-3, Standard-4, Standard-5, Standard-6, and Standard-7 regarding public and private participants.

\section{Figure 5}

Comparison of Participants Belonging to Public and Private Institutions on Standards

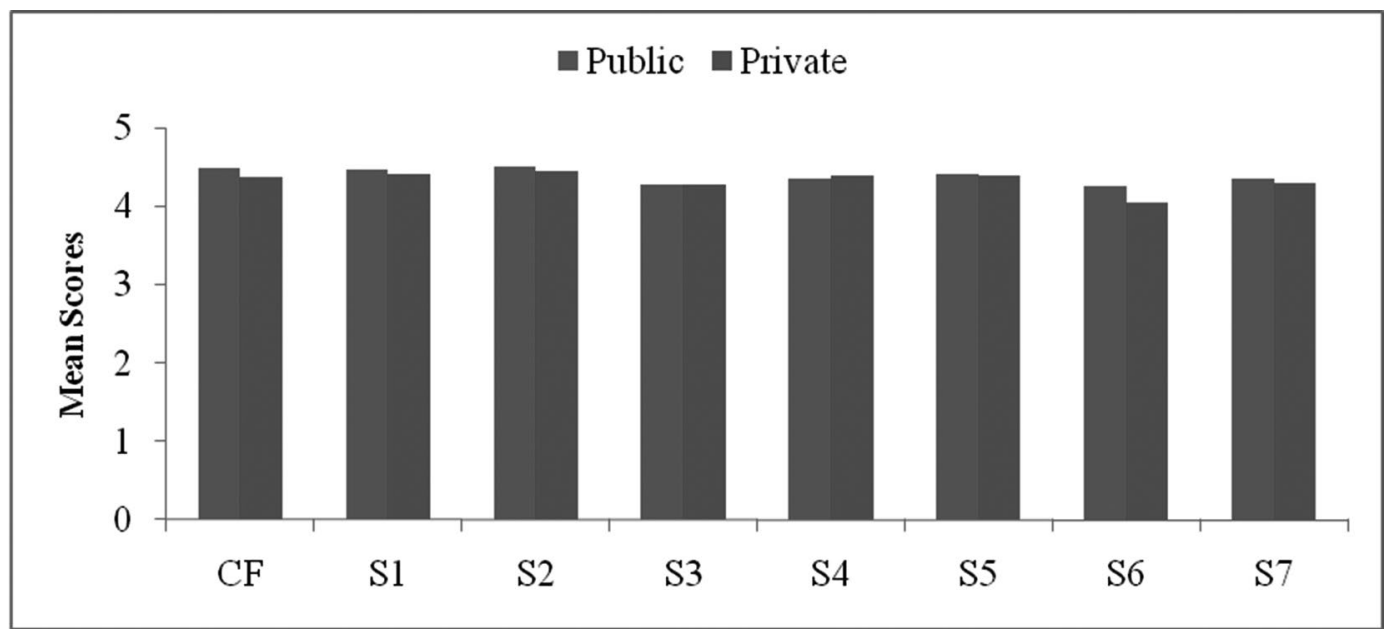




\section{Table 8}

Comparison of Participants of Different Experience Type on Standards

\begin{tabular}{|c|c|c|c|c|c|c|c|c|}
\hline \multirow[b]{2}{*}{ Standards } & \multicolumn{2}{|c|}{ Evaluator } & \multicolumn{2}{|c|}{$\begin{array}{c}\text { Teacher } \\
\text { Evaluator }\end{array}$} & \multicolumn{2}{|c|}{$\begin{array}{c}\text { Dean/Director } \\
\text { /HOD }\end{array}$} & \multicolumn{2}{|c|}{$\begin{array}{l}\text { One-way } \\
\text { ANOVA }\end{array}$} \\
\hline & M & SD & $\mathbf{M}$ & SD & M & SD & $\mathbf{F}$ & $\mathbf{p}$ \\
\hline $\mathrm{CF}$ & 4.44 & 0.59 & 4.37 & 0.60 & 4.57 & 0.55 & 1.64 & .196 \\
\hline S1 & 4.45 & 0.49 & 4.41 & 0.49 & 4.47 & 0.49 & 0.25 & .780 \\
\hline S2 & 4.50 & 0.43 & 4.46 & 0.47 & 4.44 & 0.44 & 0.18 & .839 \\
\hline S3 & 4.38 & 0.55 & 4.25 & 0.56 & 4.17 & 0.78 & 1.33 & .268 \\
\hline S4 & 4.35 & 0.48 & 4.37 & 0.59 & 4.36 & 0.62 & 0.02 & .976 \\
\hline S5 & 4.44 & 0.49 & 4.40 & 0.55 & 4.34 & 0.53 & 0.33 & .722 \\
\hline S6 & 4.22 & 0.79 & 4.23 & 0.79 & 3.79 & 1.12 & 3.76 & .025 \\
\hline S7 & 4.48 & 0.54 & 4.28 & 0.54 & 4.23 & 0.71 & 2.62 & .076 \\
\hline
\end{tabular}

One-way ANOVA was conducted to compare differences in standards of participants belonging to different experience types. The results of One-way ANOVA indicated that there was no significant difference on the statistically significant difference on Conceptual framework Standard-1, Standard-2. Standard-4, Standard-5, Standard-7 regarding participants belonging to different designations. There was a statistically significant difference on Standard-6, belonging to different experiences type. Dean/Director/HOD was less confident about the impact of the accreditation program on the improvement of teacher education programs as compared to Evaluator and Teacher Evaluator.

\section{Figure 6}

Comparison of Participants Belonging to Different Designation on Standards

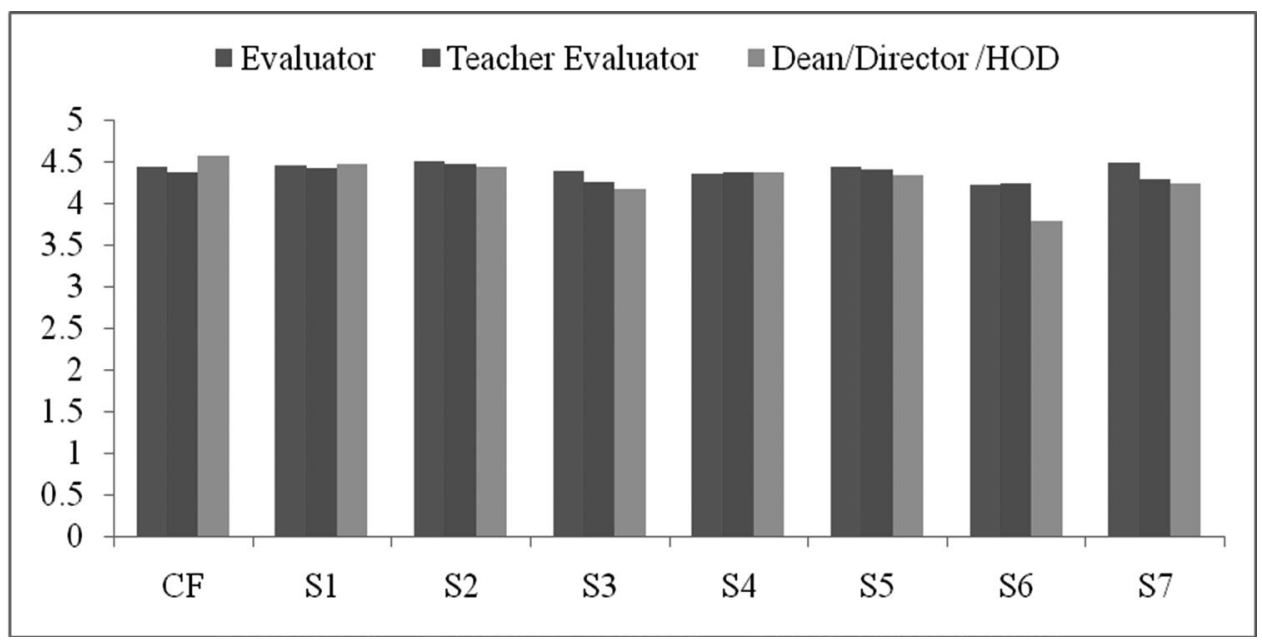




\section{Findings}

The findings of the study were drawn from the analysis of data collected from all provinces of Pakistan.

1. Results from demographic information of participants indicate the percentage of the participants selected from all provinces of Pakistan with the highest percentage from Sindh (25.6\%) and least from AJK (4.1\%)

2. Most of the participants were male $(58.5 \%)$ and a high percentage of participants belonged to universities.

3. Most of the participants $(55.4 \%)$ had experience as a teacher educator and most of the participants (43.1\%) were assistant professors in their respective institutions.

4. In addition to this, the participants having experience as both evaluator and member of the accreditation committee have the relative majority of $35.4 \%$. Participants belonged to both the private and public sectors in an almost equal ratio of $53.8 \%$ and $46.2 \%$.

5. The majority of participants $(81.5 \%)$ said that the accreditation process has a moderate impact on the improvement of teacher education programs.

6. While $27(13.8 \%)$ participants supported the statement of High Impact improvement of teacher education programs.

7. It was an important question to the participants about Program Accreditation whether it helped or not to improve teacher education program. One hundred twenty-six (65.1\%) participants said that program accreditation improved teacher education programs

8. While $60(30.8 \%)$ participants said that program accreditation sensitized about the accountability of staff, administration, and students.

9. The response of participants about the objectives of the teacher education program is that about $179(92.3 \%)$ participants have chosen moderate or high impact.

10. The overall response of participants regarding the impact of the conceptual framework of institution represents that about 360 (91.8\%) respondents have responded to this statement as high or moderate impact on the improvement of teacher education programs. 
11. The information regarding responses of participants on curriculum and instruction: When asked about the impact of revision/updating of teacher education curricula about $180(92.3 \%)$ participants chose moderate or high impact. One hundred and eight-six (95.4\%) participants supported the statement that curriculum content concerning its relevance to the teaching profession has a moderate or high impact on the improvement of teacher education. And $183(93.8 \%)$ participants said that the curriculum content concerning the variety and sharing of learning experiences of teacher educators have a high or moderate impact on the improvement of teacher education programs.

12. One hundred and seventy-nine $(91.8 \%)$ participants supported the statement that curriculum content about its compatibility with the changing and emerging local and global needs of society has a moderate or high impact on the improvement of teacher education.

13. Similarly, the majority of the participants about $180(92.3 \%)$ respondents responded to the statement that curriculum documents about the duration of the programs, semesters, and credit hours have a high or moderate impact on improvement on teacher education.

14. When asked about the impact of quality of the teaching and learning process in the institution, $189(96.9 \%)$ respondents supported the statement by choosing it as the high or moderate impact on the improvement of teacher education.

15. Comparison of participants belonging to public and private sectors on standards. Independent samples t-test was conducted to compare participants belonging to public and private sectors on standards. There was no statistically significant difference on Conceptual framework Standard-1, Standard-2, Standard-3, Standard-4, Standard-5, Standard-6, and Standard-7 regarding public and private participants.

\section{Discussion}

The systematic review of empirical studies on the impact of accreditation helped identify the literature gaps during this research area. The subsequent three details merit attention: First, further research studies in diverse contexts are required because the studies are not consistent in terms of the impact of accreditation. It 
should even be noted that since no similar research has been found within the NACTE context, it is worthwhile to research this area.

Secondly, most of the studies reviewed focused only on examining institutional staff's perceptions and attitudes generally towards EQA without systematically seeking to look at the explanations behind such perceptions and attitudes.

For instance, some studies (e.g., Anderson, 2006; Blythman, 2001; Cartwright, 2007; Cheng, 2011) reported the resistance of academics towards EQA, but the underlying reasons for these attitudes displayed by institutional staff were still not clear in these studies. A further gap refers to the very fact that although there is a variety of studies examining audits or EQA, there are only three among a complete of 18 studies examining accreditation. Furthermore, most of the studies reviewed deployed either a quantitative or qualitative research approach to deal with the research objectives, indicating that a limited number of studies used a mixed-method approach. This study will help further studies on accreditation and quality assurance system.

\section{Conclusion and Recommendations}

The current study provides the following insights for future research.

1. The impact of accreditation on teacher education institutions and program outcomes, and the reality is that the accreditation policies are subject to change during practice; furthermore, research will help build our knowledge in this area.

2. Similar research could develop the scope of the current study by including a greater number of participants from other institutions to allow a better and broader view of the data findings.

3. It will also be interesting to assess the impact of accreditation from the perceptions of different stakeholders such as institutional staff, students, enterprise, and state agencies.

4. This would provide a comprehensive picture of the extent to which the purposes of accreditation have been achieved. 
5. The current study has also shown the need for further exploration of the impact of accreditation in different fields.

This study is the first reported inquiry investigating the perceived impact of accreditation on the development of teacher education institutions in Pakistan. It conveys how stakeholders of the universities and colleges are valued and skilled in the impact of accreditation processes on their institutions. The study finds that the impact of accreditation had positive attitudes to the general effects of the accreditation regardless of each sort of accreditation. However, the study also provides evidence for a mismatch between the intentions embedded within the policies and therefore the measures implemented.

The study contributes to a limited body of literature in Pakistan. More importantly, the study suggests a variety of important implications for policy and practice. It is inferred from the study that enhancing the effectiveness of accreditation requires sustained efforts at both the national and institutional levels. The event of quality assurance and accreditation systems is going to be an extended journey. However, for the many intended outcomes of accreditation, it seems well worth an effort.

\section{References}

Alstete, J. W. (2004). Accreditation Matters: Achieving Academic Recognition and Renewal. ASHE-REIC Higher Education Report, 30(4).

Anderson, G. (2006). Assuring quality/ Resisting quality assurance: Academics' responses to 'quality' in some Australian universities. Quality in Higher Education, 12(2), 161- 173.

Banji, F. (2010). Quality assurance in higher education: The need for a paradigm shift. http://www.merit.unu.edu/MEIDE/papers/2011/1299015629_JF.pdf.

Blessing, L. T., \& Chakrabarti, A. (2009). DRM: A design research methodology (pp. 1342). Springer.

Blythman, M. (2001, May). Academic staff and the process of subject review: some experiential qualitative accounts from 'backstage'and 'under the stage'. In 6th QHE Seminar: End of Quality (pp. 25-26).

Botha, J., Favish, J., \& Stephenson, S. (2008). Institutional Audits: A comparison of the experiences of three South African Universities. Quality in Higher Education, 14(1), 29-53. 
Bradley, J. (1993). Methodological issues and practices in qualitative research. The Library Quarterly, 63(4), 431-449.

CAEP (2013a). CAEP Accreditation Standards. Washington, DC: Council for the Accreditation of Educator Preparation.

CAEP (2013b). Annual Report to the public, the states, policymakers, and the education profession. Washington, DC: Councilfor the Accreditation of Educator Preparation.

CAEP (2013c). Policy Manual. Washington, DC: Council for the Accreditation of Educator Preparation.

Carmichael, R. (2001, May). Impact of external quality assurance on educational standards: an Australian case study. In 6th Quality in Higher Education Seminar, Birmingham.

Carr, S., Hamilton, E., \& Meade, P. (2005). 'Is it possible? Investigating the influence of external quality audition university performance'. Quality in Higher Education, 11(3), 195-211.

Cartwright, M. (2007). The rhetoric and reality of "quality" in higher education. Quality Assurance in Education, 15(3), 287-301.

CEDEFOP (2009). Accreditation and quality assurance in vocational education and training Selected European approaches. Luxembourg: Publications Office of the European Union.

CEDEFOP (1996). Quality issues and trends in vocational education and training in Europe. Luxembourg: Publications Office of the European Union.

CHEA (2010). The Value of Accreditation. Washington, DC: Council for the Accreditation of Educator Preparation.

Cheng, M. (2011). The perceived impact of quality audit on the work of academics. Higher Education Research \& Development, 30(2), 179-191.

Cole,A.C., \& Knowles, J.G. (2000). Researching Teaching: Exploring Teacher Development through Reflexive Inquiry. Allyn \& Bacon.

Darling-Hammond L. (2006). Securing the Right to Learn: Policy and Practice for Powerful Teaching and Learning. Educational Researcher, 35(7), 13-24.

Dill, D. D. (2000) Designing academic audit: Lessons learned in Europe and Asia.

Dill, D. D. (2012). The management of academic culture revisited: integrating universities in an entrepreneurial age. In Managing reform in universities (pp. 222-237). Palgrave Macmillan, London.

Finch (1997). Physical activity 'from our point of view': qualitative research among South Asian and black communities. Health Education Authority: London UK.

Government of Pakistan (2009). National Education Policy (2009). Islamabad: Ministry of Education. 
Government of Pakistan, Ministry of Education (2001). Education Sector Reforms Action Plan 2001-2004.

Government of Pakistan, Ministry of Education (2004). Education Sector Reform 20012-2005-6.

GTCS (2006a). Policy Statement: Accreditation of Programs of Initial Teacher Education in Scotland. General Teaching Council for Scotland.

GTCS (2006b). Memorandum on Entry Requirements to Programs of Initial Teacher Education in Scotland. General Teaching Council for Scotland.

GTCS (2013). Guidelines for Initial Teacher Education Programs in Scotland. General Teaching Council for Scotland.

Harvey, L. (2006). Impact of quality assurance: Overview of a discussion between representatives of external quality assurance agencies, Quality in Higher Education, 12 (3), 287-290.

Ingvarson, L., Elliott, A., Kleinhenz, E., \& McKenzie, P. (2006). Teacher education accreditation: A review of national and international trends and practices. Teacher Education, 1.

INQAAHE (2013). Statement on EQA. http://www.inqaahe.org/admin/files/assets/ subsites/1/documenten/1236866920_statement-on-eqa.pdf

Johnson, B., \& Christensen, L. (2008). Educational research - Quantitative, qualitative, and mixed approaches. Sage Publications.

Mohammad, R. F. (2005). A study of issues and opportunities of implementing change in a government school. Akha Khan University.

National Standards for Accreditation of Teacher Education Programs. (2009). Policy Document. Islamabad: NACTE \& Ministry of Education.

Newton, J. (2002) Views from below: Academics coping with quality. Quality in Higher education, 8(1), 39-61.

Stensaker, B. (2002) Trance, transparency and transformation: The impact of external quality monitoring on higher education. Keynote presentation at the Seventh Quality in Higher education International Seminar, Melbourne. 